\title{
ANÁLISE FACETADA: UM OLHAR FACE A MODELAGEM CONCEITUAL
}

\section{Elizabeth Andrade Duarte \\ Roberto Figueiredo Paletta de Cerqueira}

\section{Resumo}

As reflexões desse artigo concentram-se no âmbito da modelagem conceitual com foco na análise faceta, teoria esta que defende o agrupamento de termos de um dado campo do conhecimento em facetas homogêneas e mutuamente exclusivas, derivadas de suas facetas superiores por uma característica singular de divisão, sendo desenvolvida por Shiyali Ramamrita Ranganathan na década de 30. São apresentadas considerações sobre a classificação facetada como instrumento para auxiliar a representação do conteúdo intelectual em sistemas de modelagem conceitual

\section{Palavras-chave}

Modelagem conceitual; Análise facetada; Organização e uso da informação

\section{FACET ANALYSIS: SOME CONSIDERATIONS IN FACE OF THE CONCEPTUAL MODELLING}

\begin{abstract}
The reflections of this article concentrate in the scope of the conceptual modelling focusing on the facet analysis, a theory that supports the grouping of terms of a given field of knowledge in homogeneous and at the same time exclusive facets, derivatives from superior facets as a singular characteristic of division, being developed by Shiyali Ramamrita Ranganathan in the decade of 30. Considerations on the facet classification as instrument to assist the representation of the intellectual content in systems of conceptual modelling are presented.
\end{abstract}

\section{Key Words}

Conceptual modelling; Facet analysis; Organization and use of the information 


\section{CONSIDERAÇÕES INICIAIS}

No âmbito da Ciência da Informação, a análise facetada constitui um tema de pesquisa na linha de organização da informação. A investigação teórica e conceitual sobre os princípios que fundamentam a concepção dos sistemas de classificação facetada é bastante atual, tendo em vista sua utilização nas soluções de Web, carentes de uma estrutura de trabalho que possibilite a representação sistematizada de domínios de conhecimento, vinculados ou não a sistemas comerciais.

Em termos da modelagem conceitual, a análise facetada é uma importante técnica de construção de árvores de conceitos ou taxonomias, através de decomposição de classes elementares e facetas, formadoras de grupos homogêneos de indivíduos. A classificação facetada constitui-se, então, em instrumento auxiliar de representação de conceitos ideais em sistemas de hipertexto.

\section{CONCEITUANDO A ANÁLISE FACETADA}

O termo análise facetada foi introduzido primeiramente nos anos 30, em discussões da classificação bibliográfica por Ranganathan, matemático e bibliotecário indiano, para indicar a técnica de separação dos vários elementos de assuntos complexos com relação a um conjunto de conceitos fundamentais e abstratos.

Segundo Tristão (2004, p. 04) Ranganathan evidenciou a necessidade de elaboração de esquemas de classificação que pudessem acompanhar as mudanças e evoluções do conhecimento, classificando o mesmo em grandes classes e conceitos básicos, ou elementos, de acordo com certas características. Esses aspectos ou partes constituintes (que são as facetas), utilizam, como "categorias fundamentais", noções abstratas, denominadas Personalidade, Matéria, Energia, Espaço, Tempo, originando o conhecido acrônimo PMEST. Personalidade é a característica que distingue o assunto; Matéria é o material físico do qual um assunto pode ser composto; Energia é uma ação que ocorre com respeito 
ao assunto; Espaço é o componente geográfico da localização de um assunto; Tempo é o período associado com um assunto. A ordem de citação do PMEST baseia-se na idéia de concretividade.

Em termos da classificação facetada duas fontes de desenvolvimento se destacam: a) Ranganathan com sua resposta à inabilidade dos sistemas de classificação tradicionais; Prolegomena to Classification, 1967, onde expõe uma teoria complexa de classificação, com 46 cânones, 13 postulados e 22 princípios), e b) o Classification Research Group (CRG), criado em 1952 no Reino Unido com o objetivo de estudar a natureza da classificação facetada, com relevante contribuição para a pesquisa em classificação no século XX.

Tal grupo tinha seus próprios princípios, derivados de Ranganathan, a saber: a rejeição dos pressupostos de escolha das categoriais fundamentais e da ordem dessas categorias, bem como a inexistência de uma fonte de autoria única, apesar da concentração em Vickery e Austin.

Dessa forma, este artigo pretende refletir sobre uma proposta de um modelo simplificado de Análise Facetada, que incorpore os princípios de Ranganathan e do CRG, dada a importância de ambos.

\section{DESENVOLVIMENTO DA ANÁLISE FACETADA}

A análise facetada foi consideravelmente desenvolvida na década de 50 por membros do grupo de pesquisa britânico de classificação, como uma ferramenta para a organização de coleções originais nos campos científicos e sociais, tendo aumentado a eficácia das tarefas de armazenamento e recuperação de assuntos compostos e complexos. Broughton (2004) enfatiza em seus estudos que a teoria da análise facetada moderna é vista como um conjunto integrado de regras e princípios que tratam dos termos ou dos conceitos 
individuais, aglomerados em categorias para a criação de mapas bottom-up do conhecimento. Tal autor defende o pressuposto de que:

\begin{abstract}
“(...) foram identificadas categorias que são extensamente aplicáveis às terminologias de uma escala de campos sujeitos; essas categorias são geralmente funcionais e/ou lingüísticas na natureza (por exemplo entidades, processos, propriedades, operações, agentes). Os assuntos compostos e complexos são acomodados combinando conceitos individuais. Os vários formulários da sintaxe do sistema (as ligações e as réguas para requisição e combinação entre categorias) foram propostos para combinar os conceitos individuais, a maioria dos quais baseados em modelos da língua natural; o método usado na teoria britânica de classificação da faceta depende da ordem de citação".
\end{abstract}

Atualmente, a Análise Facetada é usada primeiramente para criar classificações para o arranjo físico de fontes originais (na tentativa de criação de seu substituto). A estrutura completa da classificação ou do conhecimento é construída acima dos termos individuais que são analisados em categorias e requisitados pela aplicação da sintaxe do sistema.

Embora a classificação facetada seja considerada por muitos como uma estrutura com características específicas, a análise é essencialmente uma técnica, permitindo que modelos diferentes do mesmo universo de discurso possam ser derivados, aceitando-se, desta forma, necessidades locais ou peculiares sistêmicas através de categorias e variações diferentes na sintaxe. As propriedades adicionais de objetos digitais, especialmente os não textuais e multimídia (sons e imagens) podem também fornecer dados para a análise categorial, podendo afetar a sintaxe potencial do sistema. As fórmulas desenvolvidas para a combinação dos termos e dos conceitos geram estruturas dimensionais apropriadas a um ambiente de hipertexto. As estruturas geradas da base expandida da categoria podem ser particularmente úteis em apontar ou referenciar objetos digitais, daí a necessidade de estudo dos elementos próprios da análise, aliados às técnicas computacionais de implementação dos mesmos. 


\section{ANÁLISE FACETADA NA MODELAGEM CONCEITUAL}

\section{A Teoria do CRG}

A teoria do CRG da análise facetada não está centrada em fonte única, sendo apresentada por um número considerável de trabalhos escritos por diferentes membros deste grupo. Além disso, o CRG não apresenta sua teoria da análise facetada em uma lista organizada de princípios, como fizera Ranganathan. Os princípios do CRG foram coletadas de fontes como Austin 1968; Grupo De Pesquisa 1969; Classification 1985; Foskett, A.A. 1996; Foskett, D.J. 1970, 1971, 1974; Moinhos \& Broughton 1977; Vickery 1960, 1966, 1975. Este grupo define os seguintes princípios para a análise facetada, relacionados por Spiteri (1998):

a) Princípios para a escolha das facetas:

- Princípio da Divisão: uma faceta deve representar apenas uma característica de divisão do universo superior (pai);

- Princípio da Homogeneidade e Mútua Exclusividade: as facetas devem ser homogêneas e mutuamente exclusivas, ou seja, conteúdos e características de divisão não devem se sobrepor. A mútua exclusividade é normalmente tida como redundante em relação ao Princípio da divisão;

- Princípio da Relevância: as facetas escolhidas devem ser relevantes ao propósito, assunto e escopo do sistema de classificação;

- Princípio do Apuramento: as facetas devem representar características mensuráveis, passíveis de apuração;

- Princípio da Permanência: as facetas devem representar qualidades permanentes dos do item sob divisão;

- Princípio das Categorias Fundamentais: sustenta, em oposição ao PMEST de Ranganathana, que não existem categorias fundamentais comuns a todos os domínios ou assuntos objetos de classificação. 
b) Princípios para a ordem de citação das facetas:

- Princípio da Ordem Planejada: as facetas devem ser arranjadas em uma ordem prescrita para o domínio, ou seja, não existe uma ordem geral, aplicável a todos os universos;

- Princípio da Ordem de Lista: semelhante ao princípio anterior, mas relativo às classes ou foci, também aqui uma ordem é necessária, não existindo, porém, uma única escolha ontologicamente correta. Algumas ordens são sugeridas pelo CRG, tais como simples ao complexo, complexo ao simples, espacial e geométrica, cronológica, e alfabética.

c) Princípios para a notação:

- Princípio da Ordem de Arquivamento: estatui que um sistema notacional deve refletir a ordem de arquivamento de assuntos, ou seja, a ordem de citação subjacente ao sistema de classificação;

- Princípio da Hospitalidade: uma notação deve permitir e facilitar a adição de novos assuntos, facetas, e classes em qualquer ponto do sistema de classificação.

- Princípio da Notação Ordinal/Expressiva: a notação pode ser numérica ou por expressões, o modelo do CRG não opta ou recomenda uma notação específica.

\section{O modelo simplificado de Spiteri}

A pesquisadora Louise Spiteri, da Universidade Dalhousie, Canadá, propõe em seu artigo, “A Simplified Model for Facet Analysis”, uma versão simplificada e prática da Análise Facetada, tendo realizado uma composição dos princípios do CRG e cânones, princípios e postulados de Ranganathan. 
Os princípios deste modelo são também agrupados em três planos distintos, da Idéia, Verbal e Notacional. Abaixo segue uma relação sucinta de seus componentes:

\section{Plano das Idéias;}

a) Princípios para a escolha de facetas;

- Princípio da Diferenciação: baseado no Cânone da diferenciação, de Ranganathan, que afirma a importância da distinção clara das partes componentes de uma divisão através de uma escolha precisa da característica de divisão (faceta). Um exemplo é a divisão da entidade SER HUMANO pela característica "gênero”, produzindo as classes masculino e feminino;

- Princípio da Relevância: baseado no Cânone da Relevância, de Ranganathan e no princípio homônimo do CRG, ou seja, as facetas devem refletir o propósito da classificação;

- Princípio do Apuramento: baseado no Cânone do Apuramento e no princípio homônimo do CRG;

- Princípio da Permanência: baseado no Cânone da Permanência e no princípio homônimo do CRG;

- Princípio da Homogeneidade: baseado no princípio homônimo do CRG;

- Princípio da Mútua Exclusão: baseado no princípio homônimo do CRG;

- Princípio das Categorias Fundamentais: baseado no princípio homônimo do CRG;

b) Princípios para a escolha da ordem de citação de facetas e classes;

- Princípio da Sucessão Relevante: sugere, como o Cânone da Seqüência Útil, de Ranganathan, que a ordem de citação das facetas e classes deve ser relevante para o sistema de classificação. As ordens sugeridas são a cronológica, a alfabética, a espacial ou geométrica, a simples ao complexo, a complexo ao simples, a canônica, a de quantidade crescente, e a de quantidade decrescente; 
- Princípio da Sucessão Consistente: baseado no Cânone da Sucessão Consistente, de Ranganathan;

\section{Plano Verbal;}

- Princípio do Contexto: baseado no Cânone do Contexto, de Ranganathan;

- Princípio da Aceitação: baseado no Cânone da Aceitação, de Ranganathan;

\section{Plano Notacional}

- Princípio do Sinônimo: baseado no Cânone do Sinônimo, de Ranganathan;

- Princípio do Homônimo: baseado no Cânone do Homônimo, de Ranganathan;

- Princípio da Hospitalidade: baseado no princípio homônimo do CRG;

- Princípio da Ordem de Arquivamento: baseado no princípio homônimo do CRG;

Spiteri procurou, portanto, construir um conjunto simplificado de princípios, valendo-se dos cânones, postulados e princípios de Ranganathan, acrescidos dos princípios do CRG. Ao tentar eliminar redundâncias internas e entre os modelos, enfatizou a aplicação prática e procedimental da análise facetada, da construção de soluções de classificação adequadas aos domínios modelados. Contribuiu para a divulgação dos esquemas, muitas vezes adotados intuitivamente pelos profissionais da ciência da computação.

A importância do tema na pesquisa e elaboração de software para a Internet é refletida nas tentativas de implementação do elementos do modelo através de linguagens computacionais, e.g. a XFML, como exposto no próximo item. 


\section{IMPLEMANTAÇÃO DE MODELOS NA WEB}

\section{Implementação por XML ou XFML}

A especificação da XFML é devida a Peter Van Dick, pesquisador independente. Trata-se de uma linguagem de marcação escrita em XML, sendo conveniente para a implementação de classificações facetadas em sistemas computacionais e páginas ou serviços Web. O acrônimo XFML ${ }^{1}$ significa “eXchangeable Faceted Metadata Language”, ou linguagem de dados permutáveis facetados.

A XFML contém reduzido número de tags, específicas para o registro de facetas e tópicos ou classes. O elemento facet é um container de árvores de tópicos. Além do nome, possui um atributo id (identificação).

Exemplo de código com elemento facet:

$<$ facet id = "agent” $>$ Agent $</$ facet $>$

O elemento topic é um container de classes, devendo referenciar sua faceta.

Exemplo de código com elemento topic:

$<$ facet id = “efeito_no_agente” $>$ Efeito no agente $</$ facet $>$

$<$ topic id = "terapeutico" faced_id = "efeito_no_agente” $>$

$<$ name $>$ TERAPÊUTICO $<$ /name $>$

$</$ topic $>$

$<$ topic id = "relaxante"

faced_id = “efeito_no_agente”

parentTopicid $=$ "terapeutico" >

$<$ name $>$ RELAXANTE $<$ /name $>$

$</$ topic $>$

Após a codificação da classificação em XFML, o arquivo poderá ser utilizado pelos programadores de sistemas ou sites da internet. Embora existam poucos softwares ou

\footnotetext{
${ }^{1}$ Ver http://xfml.org/.
} 
conjuntos de rotinas de tratamento específico de XFML, bibliotecas destinadas à XML podem ser usadas em substituição. Na verdade, a linguagem proposta é a própria XML com tags relacionados à Análise Facetada, não trazendo, portanto, inovações marcantes na matéria.

\section{Implementação por banco de dados}

Além do XFML ou XML, os modelos facetados podem ser implementados eletronicamente via tabelas de bancos de dados. Neste caso, as facetas normalmente corresponderão às tabelas e as classes aos registros nas mesmas. A grande desvantagem desta solução é o seu grau de propriedade. Taxonomias em XFML podem ser publicadas e gerar fontes consensuais públicas, já tabelas de bancos de dados são normalmente modeladas tendo em vista particularidades de sistemas computacionais.

\section{Quadro geral da solução Web} 1.

Um esquema de solução Web com o uso de sistemas de classificação é dado na Fig.



Fig. 1 - Esquema de solução Internet com utilização de classificação. Elaborado pelos autores. 
O diferencial está na substituição da modelagem do hipertexto, páginas HTML, tendo como fonte principal dos conceitos pertinentes não o conteúdo aplicado diretamente aos nós do hipertexto, mas sim uma base de conhecimento, produzida pela análise facetada do domínio, e representada por padrão formal particular, em arquivos de linguagens de marcação, ou tabelas de bancos de dados que traduzam as facetas e classes.

\section{CONSIDERAÇÕES FINAIS}

Ranganathan, o CRG e Spiteri, em seus modelos de Análise Facetada, procuraram sistematizar o processo lógico da distinção e elaboração de conceitos e seus relacionamentos. É de se esperar, portanto, que muitos de seus cânones, princípios e postulados nos parecem derivados do simples bom-senso, e daí, sua aplicação muitas vezes intuitiva por profissionais de outras áreas, não conhecedores dos modelos teóricos.

O mérito de tais autores concentra-se na ordenação e, já afirmada, sistematização de tais processos lógicos, além das sugestões metódicas quando da inaplicabilidade de respostas simplesmente dedutivas.

A utilização de tais princípios na modelagem de hipertextos, se não garante de forma absoluta o estabelecimento de uma rede coerente de conceitos e relações, traz, sem dúvida alguma, um formalização e um critério mais rigoroso a ser aplicado na produção de páginas, cujos conteúdos passam a ser derivados de bases de conhecimento independentes e previamente elaboradas, com o auxílio de especialistas do domínio selecionado.

Trata-se, assim, de um aprimoramento na produção de soluções Web reconhecido, inclusive, pelo consórcio gestor ${ }^{2}$ da Internet, em seu programa de desenvolvimento da web Semântica.

\footnotetext{
${ }^{2}$ Ver http://www.w3.org/.
} 


\section{REFERÊNCIAS BIBLIOGRÁFICAS}

CAMPOS, Maria Luiza de Almeida. Linguagem documentária: teorias que fundamentam sua elaboração. Niterói: EdUFF, 2001.

DENTON, William. How to make a faceted classification and put it on the web. Nov. 2003. Miskatonic University Press. Disponível em: $<\underline{\text { http://www.miskatonic.org/library/facet- }}$ web-howto.html>. Acesso em: 28 set. 2005.

FOSKETT, A.C. Análise facetada para a criação de um sistema de classificação. Belo Horizonte: Escola de Biblioteconomia da UFMG, 2000.

LIMA, Gercina Angela Borém. A análise facetada na modelagem conceitual de sistemas de hipertexto: uma revisão de literatura. Perspectivas em Ciência da Informação, Belo Horizonte, v. 7, n. 2, p. 189-196, jul/dez. 2002.

SPITERI, Louise. A Simplified Model for Facet Analysis. Canadian Journal of Information and Library Science, v.23, abril/jul 1998. Disponível em: $<$ http://iainstitute.org/pg/a_simplified_model_for_facet_analysis.php $>$. Acesso em: 10 out. 2005.

RANGANATHAN, S. R. Facet analysis: fundamental categories. In: CHAN, L. M., RICHMOND, P., SVENONIUS, E. (org.) Theory of subject analysis: a sourcebook. Littleton, Co.: Libraries Unlimited, 1985. p. 86-93 Prolegomena to library classification. 3. ed. London: 1967. v.1 
TRISTÃO, Ana Maria Delazari; FACHIN, Gleisy Regina Bóries; ALARCON, Orestes

Estevam. Sistema de classificação facetada e tesauros: instrumentos para organização do conhecimento. Ciência da Informação, Brasília, v.33, n.2, mai./ago. 2004. Disponível em: $<\underline{\text { http://www.scielo.br/scielo.php?pid=S010019652004000200017\&script=sci_arttext\&tlng }}$ =pt $>$. Acesso em: 08 nov. 2005.

VICKERY, Brian Campbell. Faceted classification: a guide to construction and use of special schemes. London: Aslib, 1960. 69 p.

Este trabalho foi apresentado inicialmente à disciplina Modelagem Conceitual para Hipertextos do PGGCI - UFMG ministrada pela professora Gercina Lima Borém em dezembro de 2005. 


\section{Elizabeth Andrade Duarte}

Mestranda em Ciência da Informação

Pós-Graduação em Ciência da Informação da UFMG

Bibliotecária Sênior Coordenadora do Sistema de Bibliotecas da Faculdade Pitágoras

calazbedt@yahoo.com.br

\section{Roberto Figueiredo Paletta de Cerqueira}

Mestrando em Ciência da Informação

Pós-Graduação em Ciência da Informação da UFMG

roberto@cerqueira.pro.br 